\title{
DO PARADIGMA FREUDIANO AO PARADIGMA LACANIANO
}

René Major

Psicanalista, presidente da Société

Internacionale d'Histoire de la Psyquiatrie et de la Psychanalyse (SIHPP)

Tradução de Simone Perelson

RESUMO: A intenção desse trabalho e anunciar a transformação do paradigma presente no pensamento psicanalítico, ao nos deslocarmos no discurso freudiano para o lacaniano. Isso se realiza pela indagação da economia da metáfora nesse discurso, que não funciona exatamente da mesma maneira, indicando então a existência de uma descontinuidade na linguagem psicanalítica na passagem de Freud para Lacan. Essa descontinuidade, no entanto, se escreve num fundo de continuidade, em decorrência da exigência teórica inaugurada pela psicanálise em que o sentido é dissolvido para lhe reconduzir à demanda que lhe é inerente.

Palavras-chave: Paradigma, metáfora, sentido.

ABSTRACT: From Freudian paradigm to Lacanian paradigm. The purpose of this paper is to underline the transformation of the paradigm present in the psychoanalytic thought when we shift from the Freudian to the Lacanian discourse that occurs by the questioning on the economy of the metaphor in that discourse, which do not work in the same way. Thus they point to the existence of the discontinuity in the psychoanalytic language when it shifts from Freud to Lacan. Yet that discontinuity is written in a background of continuity as a result of the theoretical demand inaugurated by psychoanalysis in the sense that it is dissolved to reconnect it to the demand which is inherent in it.

Keywords: Paradigm, metaphor, sense.

1 dmitamos que Freud tenha dito que o sintoma é uma meTratar-se-ia de um enunciado ao outro, de uma mudança de paradigma? Seria preciso ainda levar em conta o lugar do verbo, do verbo ser, ora em sua forma positiva — o sintoma é uma metáfora - ora em sua forma negativa — dizê-lo não é uma metáfora - para articular o que liga a metáfora à questão do ser. 
Lacan estaria empreendendo a retirada da metáfora do discurso freudiano sobre a metáfora ou do discurso metafórico freudiano? Lacan seria, então, uma metáfora de Freud, seu sintoma, o nome de Freud surgindo como literalmente aquele que diz a verdade de Lacan, verdade que colocaria a língua psicanalítica sob o signo de uma literalidade fundamental a ser escutada, mais do que sob o signo de uma metaforicidade a ser decifrada?

Esta seria, em suma, a hipótese que daria conta de uma transformação da língua psicanalítica desde Freud até Lacan. Mas não é sob a forma de uma alternativa que se apresenta esta transformação. A continuidade da transformação se referiria antes à necessidade que tem a psicanálise de inaugurar incessantemente um modo de pensamento que dissolve por princípio o sentido, reconduzindo-o à demanda que lhe é inerente.

\section{I}

A primeira mudança de paradigma em Freud provém da descoberta da transferência a partir do tratamento por seu amigo Breuer, segundo o método catártico, de sua paciente chamada Anna O. Quando o tratamento pareceu terminado, “desencadeou-se bruscamente na jovem um estado de 'amor de transferência' que Breuer não atribuía mais a seu ser-doente, de modo que ele distanciou-se dela com pavor” (FREUD, 1925/1984, p.46). Deste incidente deplorável, Freud fará um feliz contratempo, ao considerar que "este amor de transferência” é, ao menos em parte, um erro quanto à pessoa; que se relaciona também ao sintoma e liga-se às lembranças patogênicas. Mas se postula a existência de uma "falsa relação", isto não o impede de considerar que é através deste "mau casamento" que será atingida a origem do sintoma. Em outras palavras, é a natureza sexual da transferência que revelará a natureza sexual da "histeria" e a nova "neurose" artificialmente criada pela transferência será o objeto da análise. O método analítico afasta-se, assim, da descrição pretensamente objetiva da nosografia psiquiátrica, pois o sintoma é constituído por uma rede de significantes que se ligam ao inconsciente e, ao se colocar no trajeto destes significantes, o analista se encarrega de representar parte dos sintomas. A representação do analista entra, portanto, na cadeia do discurso inconsciente, como uma substituição de significantes. O nome do analista torna-se, durante o tempo da análise, a metáfora do desejo do analisando. Esta observação, por si só, justificaria que a psicanálise invente uma nova nosologia, mais específica, mais autônoma que a que usa hoje e que recorre muito à psiquiatria tradicional.

A "histeria”, cuja etiologia sexual Freud descobre, só pode ser percebida através de sua "própria histeria”. O que implica que esta última seja reconhecida como tal para que seja "neutralizada" de algum modo e que o analista venha a ocupar o lugar deixado vazio na história do paciente. Ao ocupar este lugar — aquele que permite ao sujeito existir fora das coerções de seus assujeitamentos — o analista 
revela uma atenção fundamental ao outro que antecipa as manifestações de amor ou de ódio do analisando. A psicanálise torna-se o único método que, longe de considerar essas manifestações como interruptivas, as integra na configuração do que dá acesso ao inconsciente.

Partindo da histeria para descobrir a psicanálise, o estilo de Freud — aquele no qual se inscrevem sua descoberta e sua conceitualização - permanecerá fortemente impregnado da mesma. Já quando reconhecia sua dívida para com Charcot e Chrobak a propósito da etiologia sexual da histeria, ele insinuava que uma coisa é ter uma idéia e outra desenvolvê-la, usando uma comparação da mesma natureza: "é a diferença entre um flerte leve e um casamento feito conforme a lei, revestido de todas as formalidades, e com todas as suas obrigações e dificuldades".

O uso da metáfora é bastante corrente no estilo de Freud. Para descrever o método da associação livre, por exemplo, ele utiliza a comparação do analisando com o viajante de trem que, de seu compartimento, descreveria as imagens que vê desfilarem ao observar a paisagem da janela. O inconsciente? É a parte imersa do iceberg. As transferências de sentido e substituições analógicas são freqüentes. Os próprios “conceitos" são certamente emprestados da língua tradicional, que ela seja filosófica ou literária, mas são em geral portadores de uma metáfora. Se a "representação" tem uma longa história no pensamento ocidental, ela divide com "a cena" (do sonho, do inconsciente) o uso de uma metáfora teatral. "O investimento", "o desinvestimento”, para falar da relação da energia psíquica com a representação, comportam uma analogia com a economia em geral ou a linguagem da guerra do mesmo modo que o "recalcamento" fora das fronteiras da consciência ou a "resistência" que se opõe ao inconsciente. Quando se trata do "sujeito" na psicologia das massas, ele é comparado a uma célula no seio do organismo vivo, na pluricelularidade do corpo social ou do "Estado celular". Quanto ao "neurótico”, estamos com ele "como numa paisagem pré-histórica (...) Os grandes sáurios divertem-se ainda e as cavalinhas são altas como palmeiras".

Podemos retraçar na obra de Freud o trajeto analógico que vai da metáfora ao conceito. Citemos um exemplo entre tantos outros. Quando Freud interrogase sobre os pensamentos do sonho, ele os compara aos fios que correm em todos os sentidos numa rede ramificada e reticulada para ir abrigar o desejo do sonho no lugar mais denso deste entrelaçamento, o lugar onde o fio se perde na noite do desconhecido. O caminho que parte da metáfora do tecelão conduz Freud a formar o conceito de "umbigo do sonho". E este conceito é, por sua vez, portador de outras metáforas, as do corpo da mãe, do nascimento, da origem.

Seria possível objetar que certos conceitos freudianos resultam da formação neológica, tal como o Urverdrangung, a Vorstellungsrepräsentanz, o Seelenapparat, o Unheimlich, a Nachträglichkeit, etc., conceitos que precisamos freqüentemente traduzir em francês por duas palavras: refoulement originaire [recalcamento originário], représentance de 
représentation [representante de representação], appareil psychique (ou de l'âme) [aparelho psíquico (ou da alma)], l'inquiétante étrangété [o inquietante estranhamento], l'après-coup [o a posteriori]. É próprio da língua alemã poder “aglutinar" palavras da língua corrente ou substantivar infinitivos sem que isto tenha, de modo algum, um caráter estranho em relação a esta língua, como é o caso na fabricação do neologismo. Trata-se, antes, de um agenciamento metonímico, quando não de uma construção oximórica que vem aliar termos contrários. O Unheimlich traduz ao mesmo tempo o estranho e o familiar, a estranha familiaridade. De modo que nos foi possível salientar que Freud só utilizava em sua conceitualidade palavras da língua corrente. O que não é o caso, em geral, nas traduções de sua obra, mesmo se o emprego de neologismos pode ser freqüentemente reconduzido a um uso neologizante ou arcaizante da língua. ${ }^{1}$

Não se trata, evidentemente, de reduzir o que podemos chamar do estilo de Freud, tão multiforme, a uma unidade que poderia representar um uso extensivo da metáfora. Nem tampouco de mostrar que este uso da metáfora traduziria simplesmente a reflexão do objeto de observação no uso que faz da língua o sujeito observador. Nem simplesmente que a auto-observação de sua própria "histeria” se refletiria singularmente na linguagem pela qual é reconhecida “a histeria” do outro. Mas, antes de dar a entender que ao mesmo tempo que mantém sua raiz nos estudos sobre a histeria, a língua psicanalítica percorre, com Freud, o caminho que vai da metáfora ao conceito, preservando para a conceitualidade uma via de retorno à metáfora.

Se tomarmos o fenômeno descoberto por Freud no estudo sobre a "histeria", ao qual ele dá o nome de "transferência" — a saber, que o sintoma é constituído por uma rede de significantes que se ligam à memória inconsciente, ao desejo que ela recepta, e que, colocando-se no trajeto destes significantes, o analista se encarrega de representar uma parte do sintoma - a palavra que se torna um conceito central da psicanálise, Ubertragung, entra ela própria numa série semântica, portadora de metáforas concernente aos transportes, às etapas, à transmissão, à tradução. Ou seja, os deslocamentos, as mensagens, o equívoco. Para traduzir, conseqüentemente, o que era ignorado até então e que a língua transmitia, contudo, à sua revelia, Freud utilizará uma palavra da língua que dá ao fenômeno sua autonomia sem deixar de implicar o que, no seio da língua, dá conta de sua heteronomia: o inconsciente que o condiciona. Usando, de minha parte, uma comparação, direi que o conceito freudiano permite que se perceba sob sua vestimenta a nudez da metáfora de origem, como a tradução deve permitir que se pressinta, segundo as

\footnotetext{
${ }^{1}$ Como propõem os tradutores da nova edição francesa das obras completas de Freud com o uso, por exemplo, de "passagèretée, "désaide”, "consciencialité ", "rétrofantasier”, etc. BOURGUIGNON, COTET, LAPLANCHE, ROBERT (1989).
} 
palavras de Hugo von Hofmannsthal, a nudez da língua originária, tal como o corpo de uma dançarina sob os véus que a recobrem. Assim, o Liebesübertragung permitirá que se entreveja tanto a transferência amorosa e seu equívoco inerente quanto a transmissão de uma mensagem e sua necessária tradução.

\section{II}

Ao papel que desempenhou "Anna O" na descoberta de Freud, corresponde o lugar que ocupou o caso "Aimée" na criação, por Lacan, de uma nova discursividade freudiana. A história do caso "Aimée", como sabemos, servirá de base à tese de Lacan, Da psicose paranóica em suas relações com a personalidade, em 1932. Os estudos historiográficos fizeram com que conhecêssemos as verdadeiras identidades e as biografias destas duas pacientes que desempenharam um papel determinante na origem e no desenvolvimento da teoria psicanalítica. Quanto à "Aimée” de Lacan, foi Elisabeth Roudinesco $(1993)^{2}$ quem revelou sua identidade em 1986 e reconstruiu sua biografia a partir do depoimento de Didier Anzieu, o filho da célebre paciente, ele próprio analisado por Lacan. $\mathrm{O}$ acaso da vida quis que Lacan reencontrasse mais tarde sua "Aimée" como governanta na casa de seus próprios pais.

Segundo a biógrafa de Lacan, Aimée teria representado para seu psiquiatra um duplo dele mesmo: "Se, em 1931, Lacan fustigava os homens paranóicos para melhor lhes remeter ao inferno da desrazão, ele deu meia volta um ano mais tarde com o contato de uma mulher autodidata e solitária (Lacan não se dirá autodidata e self-made man, fundando uma nova escola na solidão? "Só, como sempre estive...”), cujo destino poderia ter sido o seu se, ao invés de ascender a uma carreira médica, ele tivesse pendido para a errância e o delírio. Sem dúvida, era preciso que a paranóia fosse feminina para que o filho de Alfred pudesse contemplar, no espelho que lhe segurava Aimée, uma imagem invertida de seu próprio universo familiar: um universo de normalidade onde reinava, contudo, sob o emblema do amor cotidiano, a desmesura mascarada de uma loucura de longo percurso" (1993, p.74-75). Seríamos tentados a retocar este quadro "velasquiano" se não reencontrássemos, nos últimos anos da vida de Lacan, efeitos de espelho semelhantes em sua identificação a James Joyce, que lhe lembrava os anos de sua tese: "Eu, eu comecei escrevendo Escritos inspirados. Por essa razão não tenho que me espantar muito por me reencontrar com Joyce. Ele era louco? Em quê seus inscritos foram inspirados?" (AUBERT, 1987)33.

A esta questão, ele próprio respondia — no Simpósio internacional sobre Joyce que se realizou em Paris, em 1975 — que vinha de um meio semelhante ao do

\footnotetext{
${ }^{2}$ Ver também Porge (2000).

${ }^{3}$ Um ano antes de sua tese, em 1931, Lacan havia, com efeito, publicado um texto intitulado “'Ecrits inspirés': schizophrénie”, no qual isolava a literatura dos distúrbios da linguagem de sua paciente, Marcelle C. (AUBERT, 1987).
} 
escritor, "um meio sórdido, filhos de eclesiásticos": “acreditamos que dizemos o que queremos, mas é o que quiseram os outros, mais particularmente nossa família que fala por nós". Seu interesse por Joyce se prolongaria em seu Seminário intitulado Le sinthome. O romance Ulysses será interpretado como uma autobiografia marcada pela forclusão do nome-do-pai, que a obra supria pela vontade de "fazer-se um nome”, precisamente pelo fato que "seu pai nunca foi para ele um pai".

Que esta leitura seja sobredeterminada pela própria história do leitor que é Lacan não reduz em nada sua pertinência nem esvazia sua importância. Não se lê bem senão o que se pode também ler em si. O que não quer dizer tampouco que, reencontrando-se em Joyce, Lacan se veria inteiramente projetado no espelho. Mas não é ao menos estranho vê-lo reevocar nesta ocasião" a Aimée de Minha tese" enviando para as atas do colóquio um texto que imita a este ponto a escrita joyciana: "Joyce o Sintoma a escutar como Jesus a codorna: é seu nome. Poder-se-ia esperar outra coisa de mim [d'emmoi]: ${ }^{5}$ eu nomeio [je nomme]. Que isso pareça jovem [jeune homme] ${ }^{6}$ é um incidente do qual quero tirar apenas uma coisa. É que nós somos homens [z'hommes]. O HOMEM [LOM]: ${ }^{7}$ em francês diz exatamente o que isso quer dizer. Basta escrever foneticamente: isso o fonetiza [faunétique $]^{8}$ (fon...) [faun...] à sua altura: o obsceno [l'eaubscène]. ${ }^{9}$ Escreva isso ob... [eaub...] para lembrar que o belo [beau $]^{10}$ não é outra coisa. I se acha belo [Hissecroibeau] a ser escrito como escabelo [l'essecabeau] sem o qual não há quem seja digno! Do nome de homem [hihanappat qui soit ding! ${ }^{11}$ d'nom d'hom]. O HOMEM [LOM] se homeniza [lomellise] rivalizando. Molhe, dizem-lhe, é preciso fazê-lo: pois sem molhar nada de escabelo" (LACAN, 1987).

\footnotetext{
${ }^{4} \mathrm{O}$ texto que se segue, por trabalhar basicamente com neologismos e homofonias, é praticamente intraduzível. Por esta razão, colocamos ao lado de alguns termos da tradução sugerida, que levou em consideração sobretudo o valor fonético das palavras, os termos do original em francês; e apresentamos, a seguir, o texto no original: "oyce le Symptôme à entendre comme Jésus la caille: c'est son nom. Pouvait-on s'attendre à autre chose d'emmoi: je nomme. Que ça fasse jeune homme est une retombée d'où je ne veux retirer qu'une seule chose. C'est que nous sommes z'hommes. LOM: en français ça dit bien ce que ça veut dire. Il suffit de l'écrire phonétiquement: ça le faunétique (faun...) à sa mésure: l'eaubscène. Ecrivez ça eaub... pour rappeler que le beau n'est pas autre chose. Hissecroibeau à écrire comme l'hessecabeau sans lequel hihanappat qui soit ding! d'nom d'hom. LOM se lomellise à qui mieux mieux. Mouille, lui dit-on, faut le faire: car sans mouiller pas d'hessecabeau." (N. daT.)

${ }^{5} \mathrm{O}$ neologismo d'emmoi é criado a partir da homofonia em francês entre de moi (de mim) e d'émoi (de emoção). (N. da T.)

${ }^{6} \mathrm{~A}$ homofonia aqui é com je nomme (eu nomeio). (N. da T.)

${ }^{7}$ LOM é a escrita fonética para l'homme (o homem). (N. da T.)

${ }^{8} \mathrm{O}$ neologismo faunetique é criado a partir dos termos faune [fauno ou fauna] e phonétique [fonética]. (N. da T.)

${ }^{9} \mathrm{O}$ neologismo eaubscène é criado a partir de eau [água] e obscène [obsceno]. (N. da T.)

${ }^{10}$ Beau é o anagrama de eaub. (N. da T.)

${ }^{11}$ O termo alemão Ding (coisa), utilizado por Freud e Lacan, é praticamente homófono do termo francês digne (digno). (N. da T.)
} 
Da loucura que mora no cerne do homem ao inefável desta loucura constitutiva da qual encontramos uma transposição literal na escrita neologismante, Lacan teve a constante preocupação de transmitir um saber que, tudo leva a crer, resiste a ser ensinado. Ele podia, portanto, por um lado, tentar transcrever através do neologismo a extrema singularidade da subjetividade, ao mesmo tempo que buscava, por outro lado, produzir a escrita de uma formalização que poderia assegurar a transmissão integral da experiência subjetiva. A loucura de Cantor, que lhe inspirou o matema (palavra forjada a partir do mitema de Lévi-Strauss), não devia, portanto, ser motivada por perseguições objetivas mas pela própria incompreensão matemática. Do mesmo modo que a incompreensão à que se confrontava, seu próprio ensino podia derivar tanto da dificuldade inerente ao que ele queria transmitir quanto ao ostracismo - quando não à devastação - do qual ele podia ser objeto. Lacan devia então neologismar em duas frentes. À formalização pelo “matema” associava-se o neologismo "lalangue” (alíngua) para designar a articulação do desejo à língua ou “um saber que se sabe à revelia dele próprio”.

O caso Aimée não havia largado Lacan em 1975, data na qual ele é republicado, não sem uma reinterpretação que repercutia em sua concepção do estágio do espelho, ela própria tendo sucedido à primeira publicação de sua tese sobre a psicose. É ao falar de Aimée em suas “Conferências e entrevistas nas universidades norte-americanas” (Scilicet 6/7, 1976) que ele participa a importância da psicose para todo seu trabalho: "A psicose é uma tentativa de rigor. Neste sentido, direi que sou psicótico pela única razão que sempre tentei ser rigoroso” (ibid, p.9). Esta aparente confidência poderia ser apenas impostura ou sedução, se fosse prodigalizada na restrição ao sentido em que apenas o pensamento, em todo seu rigor, confinaria à loucura. A de Aimée, de Cantor ou de Joyce. E bastaria querer encobrir a ausência de rigor como falha do pai para alcançar o vacilo da razão? Não deixa de ser verdade que para Lacan o âmago do ser é feito de loucura: "E o ser do homem, não apenas não pode ser compreendido sem sua loucura, mas ele não seria o ser do homem se não trouxesse nele a loucura como limite de sua liberdade” (LACAN, 1966, p.176). Ali onde Freud coloca a “clivagem do eu” ou a "divisão do sujeito” (segundo a tradução corrente de Ichspaltung) como meio de defesa contra a angústia intolerável, Lacan deduz uma estrutura fundamental da psyché. De modo que a extensão da noção de "divisão" podendo recobrir as duas acepções possíveis do Ich em francês, o Ego e o Eu, será feito do Ego - o que, em sua tese, Lacan chamava de "personalidade" — uma instância paranóica, em razão do desconhecimento e da susceptibilidade constitutivos dele. Ao desestabilizar este lugar das identificações imaginárias, a técnica analítica induzirá, segundo Lacan, uma paranóia dirigida” (LACAN, 1966).

A experiência da psicose nos ensina, antes de tudo, que o discurso do Outro, como tal, não chega a nós apenas sob uma forma que nos é desconhecida, mas que 
o que atravessa incessantemente a consciência não seria senão puro discurso do Outro, do qual seríamos apenas o eco. O tema, tão freqüente neste caso, de "discursos impostos" diria a verdade sobre este Narciso em nós que reencontra nas palavras da ninfa Eco as palavras de Liríope, que o engendrou forçada por Céfiso. A pulsão invocante seria o mais próximo do inconsciente. Quando Narciso responde a Eco: “Antes morrer que pertencer a você”, ele mantém o discurso que atribui a Liríope, capturada por Céfiso.

A questão para Lacan não é "Como alguém se torna louco?”, mas sim “Como se pode não ser louco?” Sobre os psicóticos que lhe eram apresentados no hospital Sainte-Anne, acontecia-lhe freqüentemente dizer: "Eis alguém perfeitamente normal." Uma entrevista exemplar destas apresentações nos foi restituída na íntegra. E o foi, de início, em uma tradução inglesa (SCHNEIDERMAN, 1980). Trata-se de um paciente que sofria de "delírio paranóico", de transmissão de pensamentos e do sentimento de ser um mutante sexual. Ele leu Nietzsche, Artaud (de quem acredita ser a reencarnação) e Lacan. Interrogado a propósito de seu nome, Gérard Primeau o decompõe para mostrar que ele escapa à regra da inscrição em uma genealogia e que a singularidade dos significantes de seu nome faz dele alguém excepcional: um geai rare. É em razão destes significantes que se criou uma ligação com uma mulher cujo nome, Hélène Pigeon, poderia inserir-se na mesma série semântica. Conseqüentemente, a ruptura com esta mulher — transposta em ruptura da cadeia significante — só poderia desencadear a desrazão. Em outras palavras, não são os nomes próprios, enquanto “insignificantes” que não se deixam traduzir, que servem neste caso para designar. É o imaginário do nome que remete ao sujeito "real". Na transferência que se estabelece nesta entrevista com Lacan, será “a jactância” que dará sinal de seu interlocutor, anagramatizando seu nome, ou assinará, como o próprio Lacan poderia ter dito, a forclusão do nome-do-pai.

A segunda coisa notável nesta entrevista é o uso extensivo de neologismos: "Venúrio" [Vénure], para reunir Vênus [Vénus] e Mercúrio [Mercure]; a suja “assastinação" [assastination], para condensar o gesto assassino [assassin] dos assistentes [assistants], “quebrourado" [l'écraseté], para dizer ao mesmo tempo o quebrado [l'écrasé] e o estourado [l'éclaté], etc. Os nomes próprios perdem sua função de designação e são os neologismos que servem como nomes próprios. Como esses últimos, eles não se deixam traduzir. São palavras "impostas”, como serão os “conceitos — nomes próprios” da teoria lacaniana que ele conhece e utiliza, aliás, cientemente: "Eu desligo do real as pessoas que estão à minha volta”, diz Gérard, “e as frases impostas (...) são pontes entre o mundo imaginário e o mundo que chamamos de real." De seu próprio nome ele extrai a palavra "prime" 12 (de Primeau) para fazer dela o significante primeiro: “É aquela que, diz ele, codifica o resto."

\footnotetext{
12 Primo, no sentido de primeiro. (N. da T.)
} 
Enfim, este jovem brilhante e culto era ao mesmo tempo poeta e matemático. Atormentado por uma mãe onipresente, telepática, e por um pai ausente e irascível, ele vivia seus conflitos transpondo-os para uma linguagem neológica ou totalmente abstrata, consciente de criar para si um mundo paralelo ao que se chama de real e tão real para ele quanto este outro mundo: "Estava obcecado pela fraternidade (...) Às questões que me colocavam, respondia muito abertamente, por séries matemáticas ou símbolos poéticos." Acabamos de ver hoje, dirá Lacan, "um caso de psicose lacaniana muito claramente. Com estes discursos impostos, o imaginário, o simbólico e o real."

Em seu ensino, ainda na época em que faz uso de uma escrita joyciana, na extrema ponta da subjetividade onde o neologismo ganha forma de nome próprio, a tentativa para Lacan de uma formalização integral desta subjetividade abandona sua articulação a uma lógica da ordem simbólica para tentar apreender o real através de uma topologia do nó borromiano. Em seu Seminário de 1976, intitulado “L’Insuque-sait”, depois de ter dito que esforçava-se em vão para ser mulher, Lacan sublinha que seu nó borromiano do imaginário, do simbólico e do real conduziu-o a distinguir estas três esferas, estes três círculos, e depois a reatá-los. Ele precisa que estes três nomes tornaram-se para ele o que Frege chama de nome próprio: “Fundar um nome próprio é algo que eleva um pouco o seu nome próprio. O único nome próprio nisso tudo é o meu.É a extensão de Lacan ao simbólico, ao imaginário e ao real que permite a estes três termos consistirem" (Ornicar12//13, 1977, p.7).

De tudo isso, deduzem-se certos axiomas que ordenam o paradigma da teoria lacaniana. 1) Na medida que o conceito não adquire autonomia com relação ao nome próprio e que sua consistência permanece tributária dele, é uma lei da autonimia que rege o discurso. 2) Vindo atar uma cadeia significante na qual se articula uma série de conceitos que extraem sua consistência do nome próprio de Lacan, a transferência sobre seu nome torna-se indissociável de uma transferência sobre sua teoria. É, em primeiro lugar, uma dupla transferência ou uma transferência do duplo. A transferência sobre o nome próprio de Lacan implica a transferência sobre toda uma cadeia de nomes próprios que, além do Simbólico/o Imaginário/o Real que datam de 1954, ganham, em seguida, cada vez mais a forma de neologismos ou de formas algébricas — tão intraduzíveis quanto o nome próprio — tal como o "parlêtre”, ${ }^{13}$ os “non-dupes errent”, ${ }^{14}$ a “une-bévue”, ${ }^{15}$ o "hommoinzin", 16 e

\footnotetext{
${ }^{13}$ Neologismo que pode ser traduzido para o português por "falesser", "falente" ou "falaser". As três traduções unem, tal como o termo em francês, o verbo "falar " e o substantivo "ser". (N. da T.)

${ }^{14}$ Fórmula que pode ser traduzida por "os não-tolos erram”. (N. da T.)

${ }^{15}$ Fórmula que pode ser traduzida por "um equívoco". (N. da T.)

${ }^{16}$ Neologismo que pode ser traduzido por "ao menos um”, tradução que não oferece, contudo, o que oferece o termo em francês, sendo este, de fato, intraduzível, pois apresenta uma semelhança de sons entre homme (homem) e au moins un (ao menos um). (N. da T.)
} 
tantos outros que extraem sua consistência do nome de Lacan. 3) Em virtude disto, a própria teoria entra num processo de desistorização, em que se instaura uma nova genealogia dos conceitos em uma língua que se destaca de seu enraizamento na língua psicanalítica "materna”.

Conseqüentemente, tentamos escapar deste grande "crocodilo" (LACAN, 1991, p.128) que é a mãe. Para Lacan, é o encontro com a Esfinge, o monstro devorador, que é decisivo para Édipo. Não é a morte de Laio. O que importa para ser admitido ao lado de Jocasta é o triunfo da prova da verdade face à Esfinge. Esta prova toca no enigma das origens, que permanece intacto no que concerne à resposta de Édipo, que é a do saber que conduz a ocupar o poder. A tragédia edipiana desvelaria assim o pano de fundo imaginal e feroz do qual ela quer se liberar. Esta crueldade seria sua verdade. E a leitura de Sófocles por Lacan diria também a verdade que serve de base à leitura feita por Freud. Assim como para Gérard Primeau, é pelo significante do nome - uma propriedade imaginária - que se estabelece nos Labdácidas uma relação de filiação: de Labdacos, “manco”, passando por Laio, “com modo torto de andar”, até Édipo, “com pé inchado”. Tal modo de articulação da filiação não exclui a sincronia das gerações: Édipo é o pai e o irmão dos filhos de Jocasta. A metáfora entrou no real, ao mesmo tempo que é abolida a função do nome do pai.

A psicanálise porta uma dupla exigência aporética: por um lado, evidenciar as formações do inconsciente até a inalcançável nudez do sentido e, por outro, dar conta do que se diz sem se dizer e do que não se diz dizendo, numa conceitualidade na qual a própria repetibilidade do conceito em contextos diferentes altera a cada vez seu sentido e indica um pertencimento sem pertencimento à classe dos conceitos dos quais ele deve dar conta. Em outras palavras, o discurso analítico deve poder explicar, em sua formalização da experiência subjetiva, as condições subjetivas desta formalização, sem negligenciar que o ponto extremo da subjetividade, que confina à loucura como âmago do ser, só pode se exprimir através da evacuação da metáfora no neologismo.

Deste modo, Lacan tenta transcrever seu próprio enigma na resposta que empresta à Esfinge: "Você me satisfez, homenzinho. Você compreendeu, é o que precisava.Vá, de aturdito não há demais, para que ele retorna a você ao meio-dito. Graças à mão que te responderá a que Antígona você chame, a mesma que pode te rasgar do que eu esfinjo sobre isso meu nãotoda, você saberá até mesmo próximo à noite te igualar a Tirésias e como ele, por ter feito o Outro, adivinhar o que te disse" (Scilicet 4, 1973).

Através do neologismo, amarram-se e intrincam-se aqui um discurso singular sobre o gozo feminino e os conceitos lacanianos da sexuação. Mas esses conceitos também extraem sua consistência do nome de Lacan. A discursividade lacaniana passará de uma tentativa de estabelecer uma ciência da letra a um ensaio 
de formalização lógico-matemática em virtude da qual o significante pertenceria a partir de então à categoria do contingente. Ainda que "o significante dos significantes" - o falo — se encontrasse ao abrigo na indivisibilidade (LACAN, 1966) da letra, ele nada mais seria senão a marca no gozo do que resiste à significação. Esta marca, marcante para o sujeito e servindo indefinidamente para re-marcar, esta marca, retirada da linguagem comum para servir, extraindo-se da língua, para designar mais do que para significar, é precisamente o nome próprio. O trajeto já se encontrava, aliás, desenhado na leitura que fazia Lacan do Booz endormi de Victor Hugo, pois o que recobre a metáfora em "seu feixe não era nem avarento nem rancoroso" é que o significante "feixe" vem abolir o nome próprio de Booz.

Se as mudanças de paradigma, operadas por Freud e por Lacan, estão ligadas em parte, com suas diferenças, a seus pontos de partida, uma inscrevendo-se no campo de uma metaforicidade a ser decifrada e a outra no campo de uma literalidade a ser formalizada, ambas refletem-se na conceitualidade, à qual cada uma recorre para dar conta destas mudanças. Criado a partir da língua corrente, o conceito freudiano extrai-se da metáfora para retornar a ela. Concebido sobretudo sob a forma do neologismo, o conceito lacaniano traduz a universalidade da extrema singularidade e extrai sua consistência do nome próprio ao qual se amarra. É também do nome próprio que espera seu desenredo.

Recebido em 6/1/2003. Aprovado em 20/1/2003.

\section{REFERÊNCIAS}

AUBERT, J. (1987) Joyce avec Lacan. Paris: Navarin.

BOURGUIGNON, A., COTET, P., LAPLANCHE, J., ROBERT, F. (1989) Traduire

Freud. Paris: PUF.

FREUD, S. (1925/1984) Sigmund Freud présenté par lui-même. Tradução para o

francês de Fernand Cambon. Paris: Gallimard.

LACAN, J. (1966) Écrits. Paris: Seuil.

"La causalité psychique".

"L’agressivité en psychanalyse".

"L'instance de la lettre dans l'inconscient, ou la raison depuis Freud". (1973) “L'étourdit", in Scilicet, n. 4. Paris: Le Seuil.

(1991) Séminaire XVII. L'envers de la psychanalyse. Paris, Le Seuil.

Ornicar n.12/13 (1977) dezembro, Paris.

Scilicet. n. $6 / 7$ (1976) Paris: Le Seuil. 
PORGE, E. (2000) Jacques Lacan, un psychanalyste. Paris: Erès.

ROUDINESCO, E. (1993) Jacques Lacan. Esquisse d'une vie, histoire d'un système de pensée. Paris: Fayard.

SCHNEIDERMAN, S. (1980) Returning to Freud. Clinical Psychoanalysis in the School of Lacan. Yale: Yale University Press.

René Major

23 Quai de Bourbon

75004 Paris França 